\title{
Development of a Mathematical Model Relating Microstructures Evolvement to Optical Appearance of Laser-induced Polychrome Oxides on Iron Substrates
}

\author{
Taotao Wu, Chenghua Wei, Menglian Zhou, Yongxiang Zhu, Mingying Song and Lijun Wang \\ State Key Laboratory of Laser Interaction with Matter, Northwest Institute of Nuclear Technology, \\ 710024, Xi'an, China \\ E-mail:wutaotao@nint.ac.cn
}

\begin{abstract}
A model was built to solve the problem of color prediction for laser color marking on metal surface based on the principle of multiple-beam interference. The microstructures evolvement of laserinduced polychrome oxides on iron substrates was investigated for the model. Firstly, surface treatments of industrial grade polycrystalline iron substrates in air were performed by irradiation with a Nd:YAG $(\lambda=1064 \mathrm{~nm})$ continuous wave laser beam. Different colored samples with different reflectivity were obtained depending on the duration of laser irradiation. Then, the surface morphology of the oxide films were studied by optical microscopy, revealing the formation of a bi-layer structure consisting of a congregate sheet layer covering a uniform layer. Compositional analyses performed by Raman spectroscopy measurements revealed the inner oxides were $\mathrm{Fe}_{3} \mathrm{O}_{4}$ and the outer oxides were $\mathrm{Fe}_{2} \mathrm{O}_{3}$ (magnetite and hematite respectively). Since the colors of the samples were determined by the light interference within the thin surface layers, the effective thickness and equivalent optical constants, i.e., refractive index $n$ and extinction coefficient $k$, are key parameters. They were determined by jointly using the spectroscopic ellipsometry and the glow discharge spectrometry. Based on the measurement results, a linear oxidation model was built to describe the growth of $\mathrm{Fe}_{3} \mathrm{O}_{4}$ and $\mathrm{Fe}_{2} \mathrm{O}_{3}$ films, and thickness-varying equivalent optical constants have been obtained. Lastly, a mathematical model based on the heat conduction equation, the oxidation kinetics and the light interference between multi-layer oxide films was used to calculate the spectrum reflectivity of the samples. The results accorded with the experimental results very well. The color of samples can be easily calculated when the spectrum of incident light was given.
\end{abstract}

DOI: $10.2961 /$ jlmn.2016.03.0015

Keywords: laser oxidation, laser color marking, surface coating, iron oxide, optical constant

\section{Introduction}

Laser color marking is currently of increasing interest for its potential in fabricating identification tags, anticounterfeiting and decorative applications [1-10]. There are several methods of laser color marking reported in the literatures [11]. Traditionally, laser color marking can be achieved by laser-induced oxidation on metal surface. When metal substrates are irradiated by a laser beam and heated to a high temperature, the thermal oxidation reaction will be stimulated and the metal oxide films grow. Due to the transparency in the visible light of these metal oxide films, the colored appearance of the metal surfaces are often attributed to the interference of the reflected white light.

Researchers have demonstrated colored metal oxide films on different metals such as $\mathrm{Ti}$ [9] and stainless steel [8]. By controlling the laser power, duration and scan speed, a large palette of colors can be produced $[4,5]$. Laserinduced coloration or oxidation of metals is an example of high-temperature oxidation and corrosion of metals, which has been studied for many years [12]. In theory, the oxidation process and the products can be foreseen based on the thermodynamic data and kinetic coefficients. But the laser irradiation is a short time and a non-isothermal process [13, 14], the real condition is more complicated than hightemperature oxidation which concerns long time and isothermal course. Recently, a large number of works have been focused on the microstructure and the phase composition of the produced oxide films [4]. The laser-induced oxidation process has been more clearly. However, the prediction of the formative colors is still not easy. The broad use of the oxide films manufactured on metals is limited. A complete model that relates oxide structure and phase composition evolution to the optical appearance is imperative [9].

This paper is concerned with the color prediction of laser-induced coloration. Surface treatments of iron substrates were performed by continuous wave laser irradiation. Different colored samples were obtained by laser irradiation with different durations. The structure, thickness and the optical constants of the oxide films were investigated to reveal the evolution process. A mathematical model was built to calculate the spectrum reflectivity of the samples, which is based on the heat conduction equation, the oxidation kinetics and the light interference between 
multi-layer oxide films $[15,16]$. The visual color of samples can be easily predicted by the model when the spectrum of the incident light was given.

\section{Materials and methods}

\subsection{Substrates}

Industrial pure polycrystalline iron substrates were used for laser irradiation experiments. The samples were circular with a diameter of $15 \mathrm{~mm}$. All test samples were ground with progressively finer SiC paper, polished with $1 \mu \mathrm{m}$ corundum, and then cleaned with alcohol in an ultrasonic cleaner. The samples had a final thickness of $0.3 \mathrm{~mm}$.

\subsection{Laser treatment}

The laser treatment system is shown in Fig. 1 (a). A continuous wave Nd: YAG fiber laser beam $(\lambda=1.06 \mu \mathrm{m})$ was used to stimulate oxide growth. The gaussian beam was broadened by a lens, limited by an aperture and then casted on the sample. The final laser spot was a symmetrical circle with a diameter of $17 \mathrm{~mm}$. The laser spot was larger than samples, which made sure that the entire sample surface was irradiated by the laser, as Fig. 1 (b) shows. The total power of the laser spot was $4.50 \mathrm{~W}$, which was determined by a power meter. The area of the laser spot was $2.27 \mathrm{~cm}^{2}$. So the power density of the laser irradiated on sample surface was $2 \mathrm{~W} / \mathrm{cm}^{2}$ approximately. An integral sphere equipped with an InGaAs detector was used to measure reflectivity. Thermocouple was positioned at the back center of the sample for temperature measurement. Six samples with different reflectivity and colors were obtained by the laser treatment system depended on the duration of laser irradiation. The reflectivity and temperature curves are shown in Fig. 2. The different oxidation states of the samples were marked at the reflectivity curve.

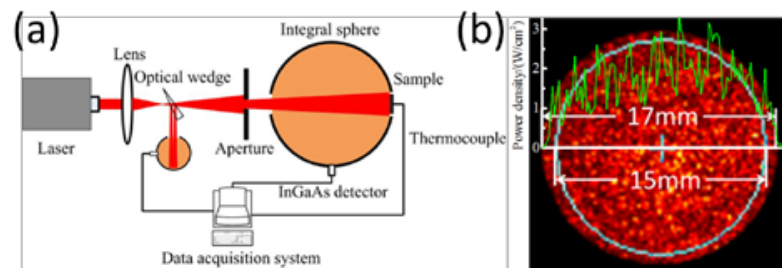

Fig. 1 (a) Block diagram of the system used for sample preparation, (b) the laser spot.

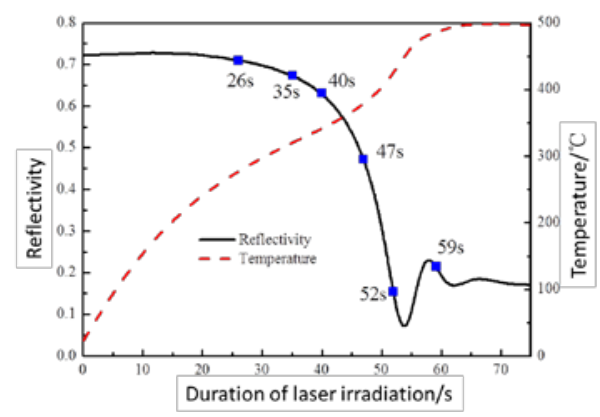

Fig. 2 Reflectivity and temperature changed with the duration of laser irradiation.

\subsection{Measurement techniques}

The morphology evolution of the oxide films were observed by an Olympus BX51RF optical microscope. The structure composition were tested by Horiba JY HR800 Raman spectrum with wavelength $325 \mathrm{~nm}$, intensity 33mw. The optical constants and thicknesses of the oxide layers were determined by Horiba UVISEL 2 spectroscopic ellipsometry with a $\Phi 2 \mathrm{~mm}$ light spot, the incident angle was $70^{\circ}$. Jointly using the glow discharge spectrometry, the thickness values were amended.

\section{Results and discussion}

\subsection{Morphology and structure evolution}

The photos of the obtained polychrome oxides were given in Fig. 3(a). With the increasing durations of laser irradiation, the colors evolved from golden to red, blue, and finally grey, which were different from Ti and 304L stainless steel substrates [2-4]. The micro-morphology evolution was shown in Fig. 3(b-g). We can see the iron surface was firstly covered by a uniform oxide layer (Fig. 3(b)). Then the second layer emerged gradually on the first layer. The second layer grew from separate islands (Fig. 3(d)) to flaky oxides (Fig. 3(e)), and finally formed a whole film (Fig. 3(f)).

\section{a)}

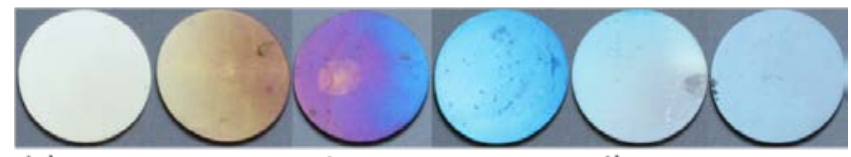

b)

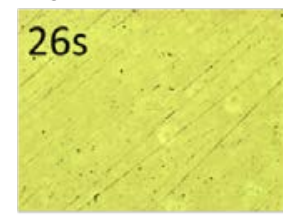

e)

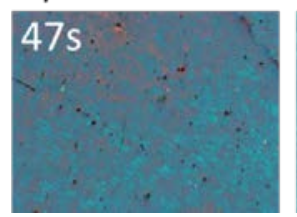

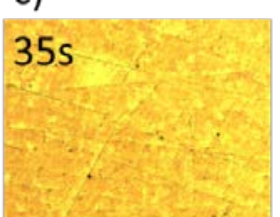

f)

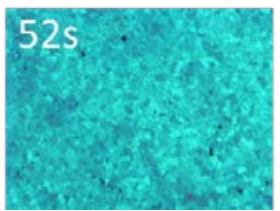

d)

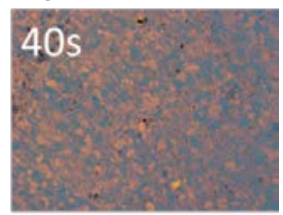

g)

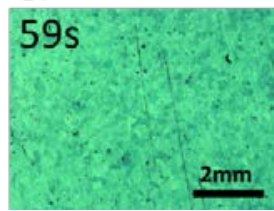

Fig. 3 (a) Photos of individual samples, (b-g) microscope images of oxide layers on the surface of iron for various durations of laser irradiation (in the same order as in point (a)).

The structure composition of the two oxide layers were tested by Raman spectrum. Considering the transparency of the iron oxide $\mathrm{Fe}_{2} \mathrm{O}_{3}$ at $633 \mathrm{~nm}$, the $325 \mathrm{~nm}$ excitation laser was chose. The testing results were shown in Fig. 4, revealing that the first formed oxide layer was $\mathrm{Fe}_{3} \mathrm{O}_{4}$ (magnetite) and the second oxide layer was $\alpha-\mathrm{Fe}_{2} \mathrm{O}_{3}$ (hematite). The penetration depth of $325 \mathrm{~nm}$ excitation laser in $\mathrm{Fe}_{2} \mathrm{O}_{3}$ is limited. The Raman signal of the inner $\mathrm{Fe}_{3} \mathrm{O}_{4}$ layer decreased along with the increasing of the outer $\mathrm{Fe}_{2} \mathrm{O}_{3}$ layer thickness for the samples of 47s, 52, and 59s. 

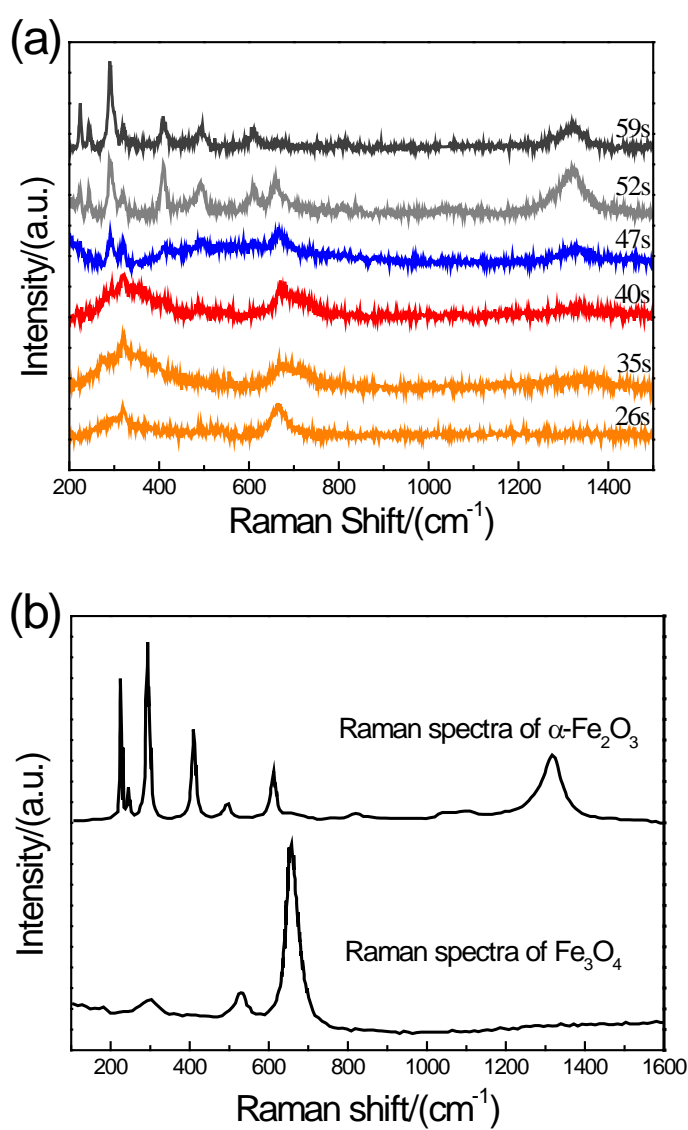

Fig. 4 (a) Raman spectrum show the structure evolution of the oxide layers $(\lambda=325 \mathrm{~nm})$, (b) Raman spectrum of $\alpha-\mathrm{Fe}_{2} \mathrm{O}_{3}$ and $\mathrm{Fe}_{3} \mathrm{O}_{4}$ for contrast.

\subsection{Optial constants evolution}

The optical constants and thicknesses of the oxide layers can be determined by the spectroscopic ellipsometry method. Before we get the right values of refractive index $n$ and extinction coefficient $\mathrm{k}$, the inversion calculations must be done, which depended on a reasonable structure model and a dispersive model of the films. Based on the analysis of the morphology and structure evolution of the oxides as shown above, the structure model of the oxide layers for inversion calculations was built as shown in Fig. 5. The new amorphous formula (NAF) model which is usually used in Ti oxides was chose as the dispersive model. The results of the inversion calculations were shown in Fig. 6 and Fig. 7. The $n_{1}$ and $k_{1}$ of magnetite for $40 \mathrm{~s}, 47 \mathrm{~s}, 52 \mathrm{~s}$ and 59s were considered the same as the $n$ and $k$ of magnetite for $35 \mathrm{~s}$. Because the first formed magnetite layer was uniform and stable as discussed previously. The reference results of high-temperature oxidation of iron were also depicted in the figure for comparison [17]. The data of the reference iron oxide comes from Ref. [17]. We can see the optical constants of laser-induced oxides of iron were different from the results of high-temperature oxidation. The refractive index $n$ and extinction coefficient $k$ of the $\mathrm{Fe}_{2} \mathrm{O}_{3}$ layer evolved with the duration of laser irradiation. We considered that this phenomenon resulted from the morphology and structure evolution of the oxides. As the $\mathrm{Fe}_{2} \mathrm{O}_{3}$ layer has experienced a process of integrating, the obtained optical constants of $\mathrm{Fe}_{2} \mathrm{O}_{3}$ in this stage were somehow the equivalent optical constants.

(a)

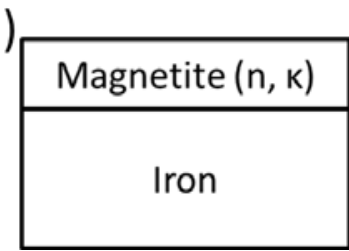

(b)

\begin{tabular}{|c|}
\hline Hematite $\left(\mathrm{n}_{2}, \mathrm{~K}_{2}\right)$ \\
\hline Magnetite $\left(\mathrm{n}_{1}, \mathrm{k}_{1}\right)$ \\
\hline Iron \\
\hline
\end{tabular}

Fig. 5 (a) Single magnetite layer model for $26 \mathrm{~s}$ and 35s,

(b) Double oxide layers model with the hematite on the magnetite for 40s, 47s, 52s, 59s.
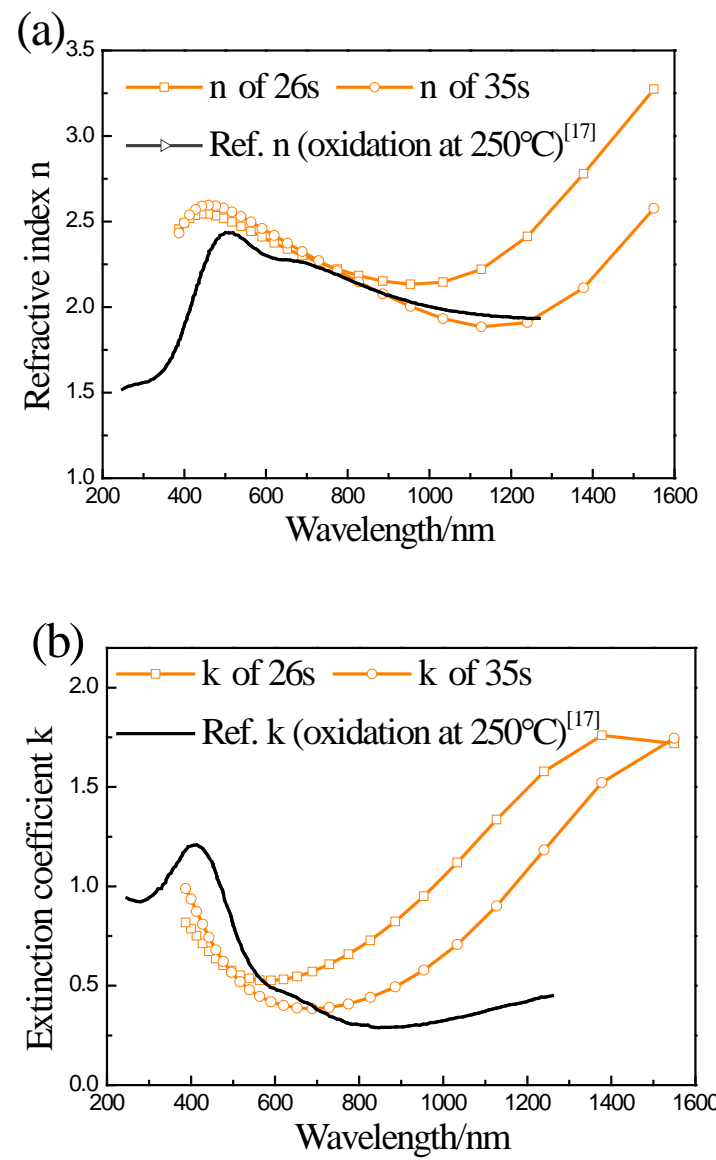

Fig. 6 (a) The refractive index $\mathrm{n}$ of the $\mathrm{Fe}_{3} \mathrm{O}_{4}$ layer for $26 \mathrm{~s}$ and $35 \mathrm{~s}$, (b) The extinction coefficient $\mathrm{k}$ of the $\mathrm{Fe}_{3} \mathrm{O}_{4}$ layer for $26 \mathrm{~s}$ and $35 \mathrm{~s}$.

\subsection{Oxidation kinetics}

The thicknesses of the oxide layers can be also obtained by the inversion calculations of the spectroscopic ellipsometry method as shown in table 1 . But the $\mathrm{Fe}_{3} \mathrm{O}_{4}$ is an absorptive oxide. When the $\mathrm{Fe}_{3} \mathrm{O}_{4}$ is too thick to be penetrated by the elliptic polarized light, the measurement value may be imprecise. So the glow discharge spectrometry was used to test the oxides. The direct results of the glow discharge spectrometry were the varying element content along with the spurting time of $\mathrm{Ar}$ ion (Fig. 8 (a)). By the integral calculation of the oxygen content 

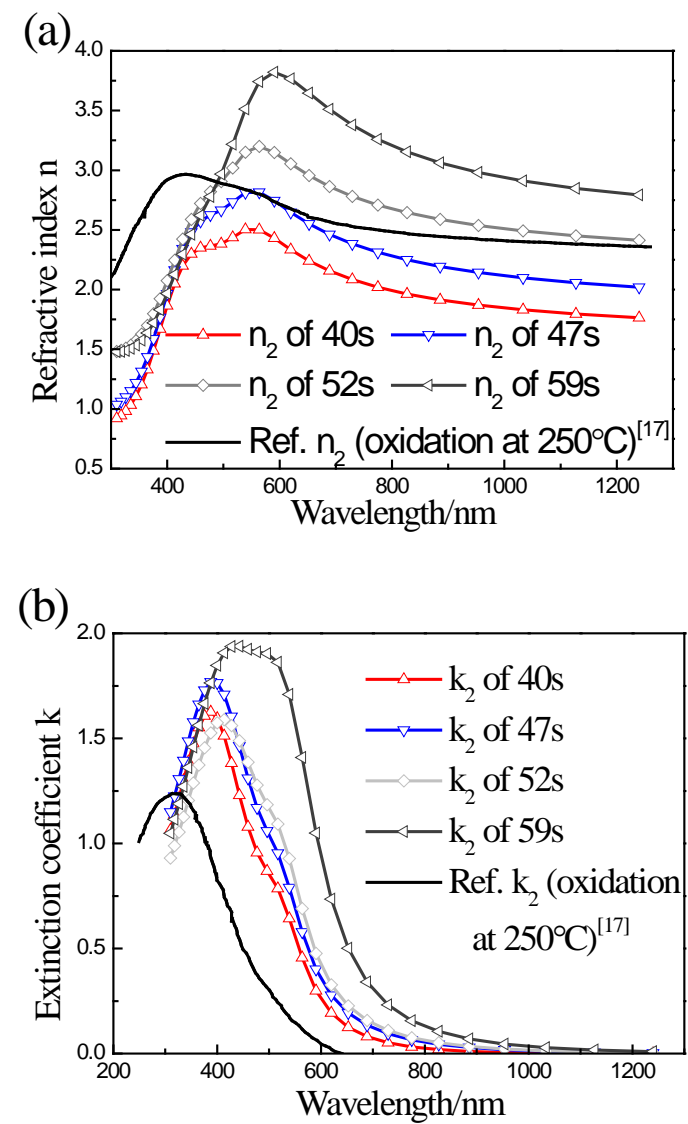

Fig. 7 (a) The refractive index $\mathrm{n}$ of the $\mathrm{Fe}_{2} \mathrm{O}_{3}$ layer for 40s, 47s, 52s, 59s, (b) The extinction coefficient $\mathrm{k}$ of the $\mathrm{Fe}_{2} \mathrm{O}_{3}$ layer for $40 \mathrm{~s}, 47 \mathrm{~s}, 52 \mathrm{~s}$, 59s.

curves, the total oxygen content of the individual sample can be obtained. The total oxygen content of different samples with different durations of laser irradiation was shown in Fig. 8 (b). Besides, referring to the crystal lattice structure of the $\mathrm{Fe}_{3} \mathrm{O}_{4}$ and $\mathrm{Fe}_{2} \mathrm{O}_{3}$, we can easily calculate the oxygen content of unit thickness [18]. With the dates in table 1 , we can obtain another curve of varying oxygen content (Fig. 8 (b)). We can see the two curves accorded with each other well when the oxides were thin. When the duration of laser irradiation is 59s, the value of ellipsometry method is smaller than the value of glow discharge method. With the oxygen content value of glow discharge method, the thickness of the $\mathrm{Fe}_{3} \mathrm{O}_{4}$ layer of 59s was amended to $169 \mathrm{~nm}$. We can see the thickness of $\mathrm{Fe}_{3} \mathrm{O}_{4}$ increased more and more rapidly, because the oxidation temperature had increased and one feature of laser-induced oxidation is "strong Arrhenius-type temperature dependences of the chemical reaction rate constants” [14].

Table 1 The thicknesses of the oxide layers by spectroscopic ellipsometry

\begin{tabular}{cccccc}
\hline $\begin{array}{c}\text { Sam- } \\
\text { ples }\end{array}$ & $26 \mathrm{~s}$ & $35 \mathrm{~s}$ & $47 \mathrm{~s}$ & $52 \mathrm{~s}$ & $59 \mathrm{~s}$ \\
\hline $\mathrm{Fe}_{3} \mathrm{O}_{4}$ & $11.2 \pm$ & $23.2 \pm$ & $27.0 \pm$ & $45.2 \pm$ & 111.4 \\
$/ \mathrm{nm}$ & 1.0 & 0.7 & 3.3 & 19.1 & \pm 9.5 \\
$\mathrm{Fe}_{2} \mathrm{O}_{3}$ & 0 & 0 & $20.4 \pm$ & $29.5 \pm$ & $22.1 \pm$ \\
$/ \mathrm{nm}$ & & & 3.3 & 9.3 & 4.3 \\
\hline
\end{tabular}
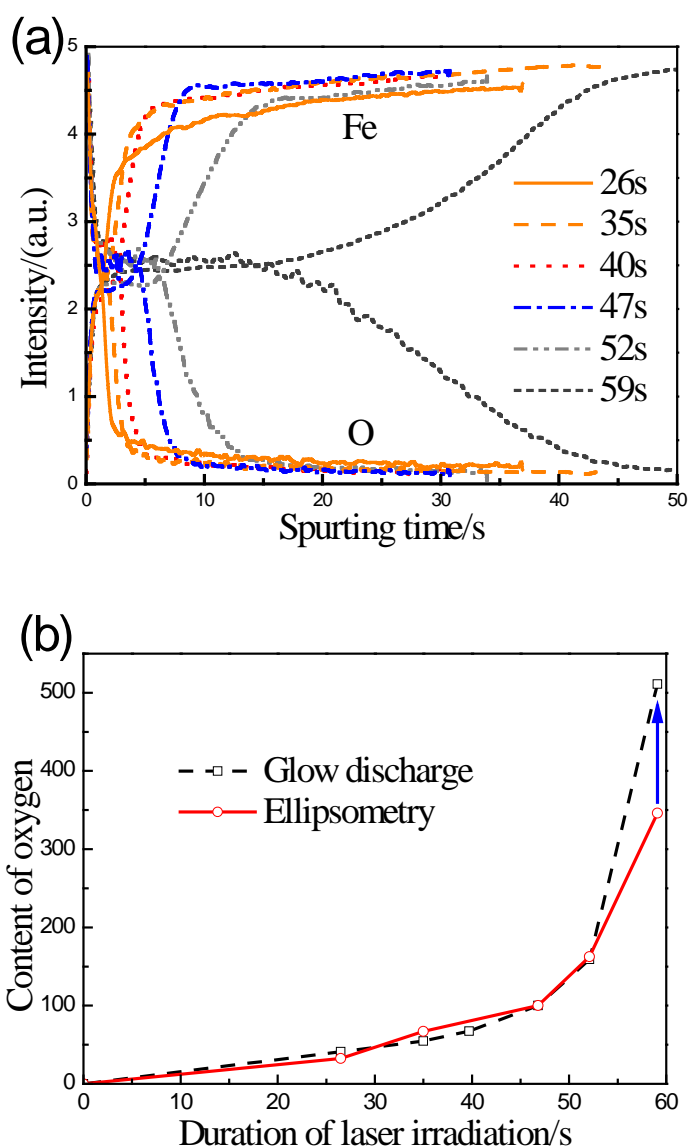

Fig. 8 (a) The result of the glow discharge spectrometry, (b) The oxygen content depending on duration of laser irradiation

As has already been discussed in Ref. [19], the layer of $\mathrm{Fe}_{3} \mathrm{O}_{4}$ resulted in more rapid increase of the thickness than $\mathrm{Fe}_{2} \mathrm{O}_{3}$, which made the $\mathrm{Fe}_{3} \mathrm{O}_{4}$ layer thicker than $\mathrm{Fe}_{2} \mathrm{O}_{3}$ [19].

Referring to the theory of high-temperature oxidation of metals [12], when the oxide film is thin at the early oxidation stage, the linear law can be used to describe the growth of the film as shown in formula (1), where $\mathrm{x}$ is the oxide thickness, $\mathrm{k}_{0}$ is the diffusion coefficient, $\mathrm{T}_{\mathrm{d}}$ is the diffusion activation energy and the $\mathrm{T}$ is the temperature in degrees Kelvin. The formula was used to fit the experimental result as shown in Fig. 9. Then the oxidation kinetics of the laser-induced oxidation of iron with the parameters in this paper was obtained.

$$
\left\{\begin{array}{l}
\frac{d x_{i}}{d t}=k \\
k=k_{0} \mathrm{e}^{-\frac{T_{d}}{T}}
\end{array}\right.
$$

\subsection{Model for color prediction}

The model for color prediction involved a heat conduction equation, an oxidation kinetics equation and a multi-beam interference formula as shown in formula (2). The first equation is heat conduction equation, in which $\mathrm{m}$ 


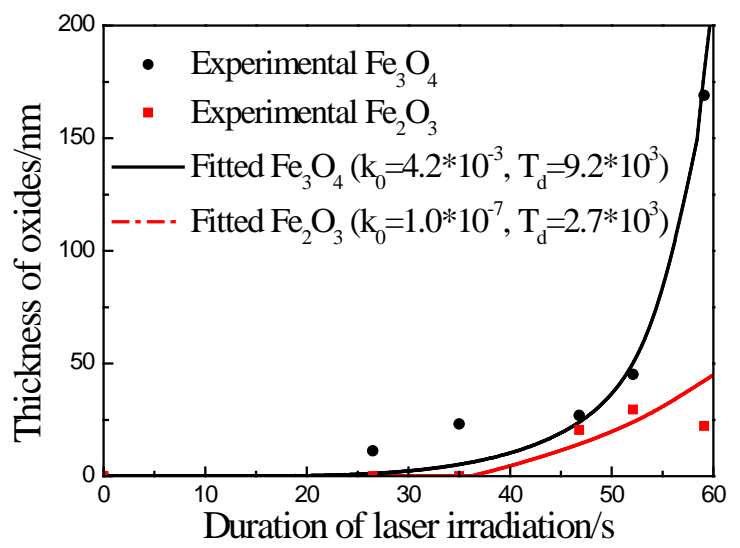

Fig. 9 The oxidation kinetics of laser-induced oxidation of iron

is the mass of the iron, $c$ is the specific heat, $R\left(x, \lambda_{0}\right)$ is the reflectivity at the laser wavelength, $\mathrm{P}_{\text {laser }}$ is the power of heating laser, $\mathrm{P}_{\text {loss }}$ is the heat loss contains the convection and thermal radiation. The second equation is the multibeam interference formula, where $\mathrm{R}(\mathrm{x}, \lambda)$ is the spectrum reflectivity of the oxides, $\mathrm{x}_{\mathrm{i}}(\mathrm{t})$ is the thickness of the oxides, $\mathrm{n}_{\mathrm{i}}(\mathrm{x}, \lambda)$ and $\mathrm{k}_{\mathrm{i}}(\mathrm{x}, \lambda)$ are the optical constants from Fig. 6 and Fig. 7. The third equation is the oxidation kinetics equation from Fig. 9. Then the spectrum reflectivity $\mathrm{R}(\mathrm{x}, \lambda)$ can be calculated when $\mathrm{m}$ and $\mathrm{P}_{\text {laser }}$ are given. Fig. 10 shows the calculated results of four typical colors in the case of this paper $\left(\mathrm{m}=417 \mathrm{mg}, \mathrm{P}_{\text {laser }}=3.5 \mathrm{~W}\right.$, incident angle $=70^{\circ}$ ). The calculation results accorded with the experimental results very well. The experimental results were measured by the Horiba UVISEL 2 spectroscopic ellipsometry with the incident angle $70^{\circ}$. So the visual color of samples can be easily calculated by the model when the spectrum of incidence light was given.

$$
\left\{\begin{array}{l}
m c \frac{d T}{d t}=\left[1-R\left(x, \lambda_{0}\right)\right] P_{\text {laser }}-P_{\text {loss }} \\
\left.R(x, \lambda)=\mathrm{F}\left[x_{i}(\mathrm{t}), \mathrm{n}_{i}(x, \lambda), \kappa_{i}(x, \lambda)\right)\right] \\
\frac{d x_{i}}{d t}=k, \quad\left(k=k_{0} \mathrm{e}^{-\frac{T_{d}}{T}}\right)
\end{array}\right.
$$

Since the principle is the same, the model can be also spread to other metals or the pulse laser color marking. In such cases, the heat conduction of the pulse laser irradiating metals would be more complex. Besides, the optical constants and the oxidation kinetics are specific and must be investigated by corresponding experiments. It should be stressed that the model in this paper can only calculate the specular reflectivity. If the object surface is not smooth, the model will not be applicable.

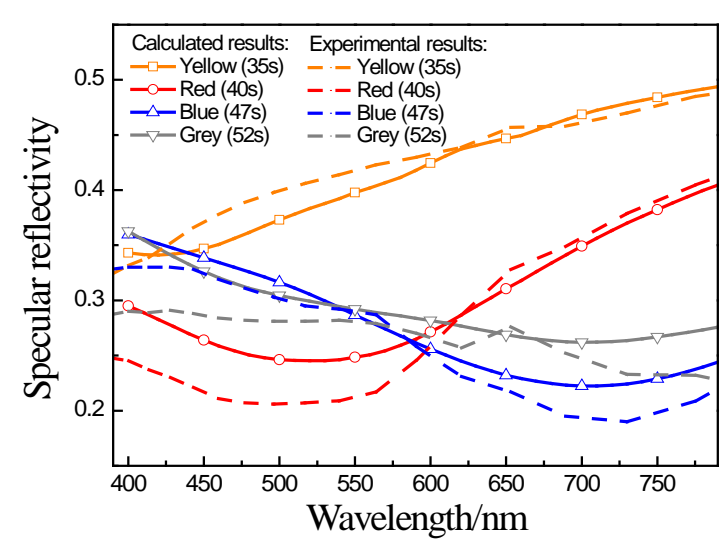

Fig. 10 The calculated and experimental results of the spectrum reflectivity

\section{Conclusions}

Different colored surfaces of iron substrates were obtained by laser irradiation with different durations. The morphology and composition analysis indicated that the absorptive $\mathrm{Fe}_{3} \mathrm{O}_{4}$ film was firstly produced and the $\mathrm{Fe}_{2} \mathrm{O}_{3}$ emerged gradually on the $\mathrm{Fe}_{3} \mathrm{O}_{4}$ film in the laser-induced non-equilibrium oxidation of iron. The $\mathrm{Fe}_{2} \mathrm{O}_{3}$ grew from separate islands to flaky oxides, and finally formed a whole film. The equivalent optical constants were determined by the spectroscopic ellipsometry which shows that the optical constants changed with the growth of the oxides. By combination of the spectroscopic ellipsometry method and the glow discharge spectrometry method, the problem of thickness measurement of the absorptive $\mathrm{Fe}_{3} \mathrm{O}_{4}$ film at hundred nanometers range has been solved. A linear oxidation model was built to describe the growth of $\mathrm{Fe}_{3} \mathrm{O}_{4}$ and $\mathrm{Fe}_{2} \mathrm{O}_{3}$ films based on the measurement values of the thickness. Finally, a mathematical model was built to calculate the spectrum reflectivity of the samples. The model is based on the heat conduction equation, the oxidation kinetics and the light interference between multi-layer oxide films. The calculated results accorded with the experimental results very well. The model correlated the microstructure evolvement to the optical appearance of laser-induced polychrome oxides on iron substrates, which can be used for color prediction or design of laser color marking on metal surfaces.

\section{Acknowledgments}

This work was supported by State Key Laboratory of Laser Interaction with Matter foundation (No. SKLLIM1501).

\section{References}

[1] H.Y. Zheng, H.X. Qian and W. Zhou: Appl. Surf. Sci., 245, (2008) 2174.

[2] Z.L. Li, H.Y. Zheng and K.M. Teh: Appl. Surf. Sci., 256, (2009) 1582.

[3] H.X. Qian, W. Zhou and H.Y. Zheng: Surf. Rev. \& Lett., 15, (2008) 675.

[4] A. Antonczak, L. Skowronski and M. Trzcinski: Appl. Surf. Sci., 325, (2015) 217. 
[5] V. Veiko, G. Odintsova and E. Ageev: Opt. Express, 22, (2014) 24342.

[6] A.P.D. Pino, P. Serra and J.L. Morenza: Thin Solid Films, 415, (2002) 201.

[7] O.M. Morales,F.C. Reyes and J.S.J. Bernal: Spectr. Acta Part A: Molecular and Biomolecular, 128, (2014) 681.

[8] D.P. Adams, V.C. Hodges and D.A. Hirschfeld: Surf. \& Coatings Tech., 222, (2013) 1.

[9] D.P. Adams, R.D. Murphy and D.J. Saiz: Surf. \& Coatings Tech., 248, (2014) 38.

[10] S.K. Lawrence, D.P. Adams and D.F. Bahr: Surf. \& Coatings Tech., 235, (2013) 860.

[11] A.A. Ionin, S. I. Kudryashov and S.V. Makarov: Appl. Phys. A: Materials Sci. \& Proc., 107, (2012) 301.

[12] N. Birks, G.H. Meier and F.S. Pettit: "Introduction to the high-temperature oxidation of metals" ed. by
Higher Education Press, ( Publisher, Beijing, 2005) p.98.

[13] L. Nanai, R. Vajtai and T.F. George: Thin Solid Films, 298, (1997) 160.

[14] M. Wautelet: Appl. Phys. A: Sol. \& Surf. 50, (1990) 131.

[15] M.I. Arzuov, A.I. Barchukov and F.V. Bunkin: Sov. J. Quantum Electron, 9, (1979) 281.

[16] F.V. Bunkin, N.A. Kirichenko and V.I. Konov: Sov. J. Quantum Electron, 10, (1980) 891.

[17] V. Goossens, J. Wielant and S.V. Gils: Surf. \& Interface Analysis, 38, (2006) 489.

[18] R.M. Cornell and U. Schwertmann: "The Iron Oxides” ed. By Druckhaus Darmstadt, (Publisher, Darmstadt, 2003) p.113.

[19] W. Schwenk and A. Rahmela: Oxidation of metals, 25, (1986) 293.

(Received: May 24, 2016, Accepted: September 26, 2016) 